\title{
Correction to: Cannabis Use in Israel: a Cross Sectional Overview of Multiple Study Groups
}

\author{
Richard Isralowitz $^{1} \cdot$ Alexander Reznik ${ }^{1}$
}

Published online: 4 June 2018

(C) Springer Science+Business Media, LLC, part of Springer Nature 2018

\section{Correction to: Int J Ment Health Addiction https://doi.org/10.1007/s11469-018-9911-y}

Figures 1 and 2 were each missing the $\mathrm{x}$-axis in this article as originally published. The original article has been corrected.

The online version of the original article can be found at https://doi.org/10.1007/s11469-018-9911-y

Richard Isralowitz

Richard@bgu.ac.il

1 Regional Alcohol and Drug Abuse Research Center, Ben Gurion University of the Negev, RADAR Center, Building \#17, 84105 Beer Sheva, Israel 